This item was submitted to Loughborough's Research Repository by the author.

Items in Figshare are protected by copyright, with all rights reserved, unless otherwise indicated.

\title{
Additively manufactured ultra-low sintering temperature, low loss Ag2Mo2O7 ceramic substrates
}

PLEASE CITE THE PUBLISHED VERSION

https://doi.org/10.1016/j.jeurceramsoc.2020.08.031

\section{PUBLISHER}

Elsevier Ltd

\section{VERSION}

AM (Accepted Manuscript)

\section{PUBLISHER STATEMENT}

This paper was accepted for publication in the journal Journal of the European Ceramic Society and the definitive published version is available at https://doi.org/10.1016/j.jeurceramsoc.2020.08.031.

\section{LICENCE}

CC BY-NC-ND 4.0

\section{REPOSITORY RECORD}

Goulas, Athanasios, George Chi-Tangyie, Dawei Wang, Shiyu Zhang, Annapoorani Ketharam, Vaidhy Vaidhyanathan, lan M Reaney, et al.. 2020. "Additively Manufactured Ultra-low Sintering Temperature, Low Loss $\mathrm{Ag}_{2} \mathrm{mo}_{2} \mathrm{O}_{7}$ Ceramic Substrates”. Loughborough University. https://hdl.handle.net/2134/12900965.v1. 


\title{
Additively manufactured ultra-low sintering temperature, low loss $\mathrm{Ag}_{2} \mathrm{Mo}_{2} \mathrm{O}_{7}$ ceramic substrates
}

\author{
Athanasios Goulas ${ }^{1 *}$, George Chi-Tangyie ${ }^{2}$, Dawei Wang ${ }^{3}$, Shiyu Zhang $^{1}$, Annapoorani Ketharam ${ }^{2}$, Bala \\ Vaidhyanathan ${ }^{2}$, Ian M. Reaney ${ }^{3}$, Darren A. Cadman ${ }^{1}$, Will G. Whittow ${ }^{1}$, John (Yiannis) C. Vardaxoglou ${ }^{1}$, \\ Daniel S. Engstrøm ${ }^{1}$
}

${ }^{1}$ Wolfson School of Mechanical, Electrical and Manufacturing Engineering, Loughborough University, LE11 3TU, United Kingdom 2Department of Materials, Loughborough University, Loughborough, LE11 3TU, United Kingdom ${ }^{3}$ Department of Materials Science and Engineering, University of Sheffield, Sheffield, S1 3JD, United Kingdom.

*a.goulas@lboro.ac.uk

\section{ABSTRACT}

Ultra-low sintering temperature silver molybdenum oxide $\left(\mathrm{Ag}_{2} \mathrm{Mo}_{2} \mathrm{O}_{7}\right)$ ceramics have been printed using direct ink writing (a material extrusion additive manufacturing process) for the first time. An optimum densification conditions of $460^{\circ} \mathrm{C} / 2 \mathrm{~h}$ was determined, resulting in relative permittivity, $\varepsilon_{r}=13.45$, dielectric loss, $\tan \delta=0.0005$, microwave quality factor, $Q \times f=17,056 \mathrm{GHz}$ and the temperature coefficient of resonant frequency $\tau_{f}=-121 \mathrm{ppm} /{ }^{\circ} \mathrm{C}$. The results were comparable to the dielectric properties of conventionally fabricated ceramics. A series of metal/ceramic antenna designs were produced via dualprinting and co-firing, to demonstrate the potential of $\mathrm{Ag}_{2} \mathrm{Mo}_{2} \mathrm{O}_{7}$, to be used as a co-firable dielectric material for functional integrated circuits and/or microwave RF devices through multi-material direct ink writing.

Keywords: additive manufacturing; 3D printing; LTCC; silver molybdenum oxide; microwave ceramics 


\section{INTRODUCTION}

Microwave dielectric ceramics are a large part of the modern wireless telecommunications industry; being the materials of choice for many applications, such as substrates, antennas, filters, capacitors and couplers where a specific combination of properties are required to achieve the best performance $[1,2]$. Critical material properties are relative permittivity $\left(\varepsilon_{r}\right)$ whose optimum value is specific to the application, low dielectric loss $(\tan \delta)$, high-quality factor $(Q \times f)$ and near zero value of the temperature coefficient of resonant frequency $\left(\tau_{f}\right)$ [3-5]. Sebastian et al. collated more than 4000 different electroceramic compounds with suitable properties for microwave applications [6]. However, most microwave ceramics have sintering temperatures above $1000{ }^{\circ} \mathrm{C}$ [7-9], limiting their potential to be co-fired with common electrode materials, such as aluminium, copper or silver. Low-temperature co-fired ceramics (LTCCS) can be densified below $1000^{\circ} \mathrm{C}$, offering the potential for making passive integrated circuitry [10-13] with embedded electrodes and electronic components to achieve miniaturised, lighter and overall higherperformance RF devices [14].

Molybdenum oxide based compounds are important for the fabrication of ultra-low sintering temperature ceramics and devices [15-17]. Zhou et al. first investigated the $\mathrm{Ag}_{2} \mathrm{O}_{3}-\mathrm{MoO}_{3}$ binary system that contained the phases $\mathrm{Ag}_{2} \mathrm{Mo}_{4} \mathrm{O}_{13}, \mathrm{Ag}_{2} \mathrm{Mo}_{2} \mathrm{O}_{7}$ and $\mathrm{Ag}_{2} \mathrm{MoO}_{4}$. They studied the wide band dielectric spectra and microwave dielectric properties of $\mathrm{Ag}_{2} \mathrm{MoO}_{4}$, together with its chemical compatibility with common electrode materials. When sintered at $450^{\circ} \mathrm{C}$ for 4 hours, $\mathrm{Ag}_{2} \mathrm{MoO}_{4}$ ceramics gave $\varepsilon_{r}=8.08, Q \times f=17,000$ $\mathrm{GHz}$ and $\tau_{f}=-133 \mathrm{ppm} /{ }^{\circ} \mathrm{C}[18]$. Zhang et al. reported the synthesis, microwave dielectric and physical properties of both $\mathrm{Ag}_{2} \mathrm{Mo}_{2} \mathrm{O}_{7}$ and $\mathrm{Ag}_{6} \mathrm{Mo}_{10} \mathrm{O}_{33}$ ultra-low sintering temperature ceramic phases. $\mathrm{Ag}_{2} \mathrm{Mo}_{2} \mathrm{O}_{7}$ ceramic was fired at $460{ }^{\circ} \mathrm{C}$ for $4 \mathrm{~h}$ resulting in $\varepsilon_{r}=13.3, Q \times f=25300 \mathrm{GHz}$ and $\tau_{f}=-142 \mathrm{ppm} /{ }^{\circ} \mathrm{C}$. It was also shown that $\mathrm{Ag}_{2} \mathrm{Mo}_{2} \mathrm{O}_{7}$ is chemically compatible with $\mathrm{Ag}$ and $\mathrm{Al}$ and therefore may be co-fired. [19]. The $\mathrm{Ag}_{2} \mathrm{Mo}_{2} \mathrm{O}_{7}$ has attracted attention in the last few years due to its multifaceted potential to be used as a visible light active photocatalyst [20-22], an anode material for sodium-ion energy storage devices [23] and as an additive for improving the tribological properties of metal in high-temperature applications $[24,25]$. In this study however, we recognize that $\mathrm{Ag}_{2} \mathrm{Mo}_{2} \mathrm{O}_{7}$ is an excellent candidate for metal/ceramic integrated microwave devices due to its low-temperature sintering and chemical compatibility with $\mathrm{Ag}$, its high $\varepsilon_{r}\left(\sim 13\right.$, the highest in the $\mathrm{Ag}_{2} \mathrm{O}_{3}-\mathrm{MoO}_{3}$ system $)$ and its high $Q \times f(\sim 20,000 \mathrm{GHz})$. 
Additive manufacturing (AM), commonly known as 3D printing, holds the potential to revolutionise electronics manufacturing by being able to combine printing of dissimilar materials in a single process and also realising complicated electronic devices that would normally require significant effort, manufacturing time and cost to integrate [26-28]. However, additively manufactured components do not always achieve bulk material properties due to process-specific limitations [29]. As a result, post-processing is often required to achieve desirable performance and repeatability.

This study investigates the microwave dielectric properties of additively manufactured $\mathrm{Ag}_{2} \mathrm{Mo}_{2} \mathrm{O}_{7}$ samples through direct ink writing; a material extrusion additive manufacturing process. The effect of sintering temperature on the physical, microstructural and dielectric properties is discussed. 


\section{MATERIAL \& METHODS}

\subsection{Materials}

The $\mathrm{Ag}_{2} \mathrm{Mo}_{2} \mathrm{O}_{7}(\mathrm{AMO})$ powder was synthesised using the solid-state reaction method. High purity raw chemicals, $\mathrm{Ag}_{2} \mathrm{O}$ (99.5\%, Acros Organics) and $\mathrm{MoO}_{3}$ (>99\%, Acros Organics) were weighed stoichiometrically $\left(\mathrm{Ag}_{2} \mathrm{O}: \mathrm{MoO}_{3}=1: 1\right)$ and then ball-milled in isopropanol for a duration of 4 hours. Afterwards, the dried mixed powders were calcined $4 \mathrm{~h}$ at $430{ }^{\circ} \mathrm{C}$. The calcined powder was then milled using a rotary mill and sieved through a $100 \mu \mathrm{m}$ aperture laboratory sieve.

Silver paste (PMC3, Mitsubishi Materials Trading Corp., Japan) was used as the electrode material to 3D print the patch antenna. The paste comprised a $90 \mathrm{wt} . \%$ solid loading of spherical Ag particles of $<1 \mu \mathrm{m}$ in diameter, mixed in a water-soluble binder system.

\subsection{Ceramic paste synthesis}

A binder mix consisting of ethylene glycol diacetate (3.3 wt.\%, Sigma Aldrich, UK) as dispersant, methylcellulose (1.6 wt.\%, Sigma Aldrich, UK) and propylene carbonate (0.9 wt.\%, Sigma Aldrich) as viscosity modifier and binder, diisononyl phthalate (1.3 wt.\%, Sigma Aldrich, UK) as plasticiser, and ammonium lauryl sulphate ( $<0.5$ wt.\%, Sigma Aldrich, UK) as surfactant was prepared. The AMO powder was slowly incorporated into the binder followed by mixing and then topped up with de-ionised water. The paste was homogenised thrice using a planetary mixer (Thinky ARM 310, Thinky Inc., Laguna Hills, California USA) at $1500 \mathrm{rpm}$ for 2 mins. The total solids content in the paste was $78.96 \mathrm{wt} . \%$.

\subsection{Additive manufacturing and post-processing.}

All additively manufactured test samples were made using a multi-process additive manufacturing kit (High-Resolution Engine, Hyrel3D, Norcross, GA, USA), equipped with a syringe dispensing module (SDS5, Hyrel3D, Norcross, GA, USA), using 5 ml luer-lock syringes (Becton Dickinson, Franklin Lakes, New Jersey, USA) and $500 \mu \mathrm{m}$ metallic needles of $18.25 \mathrm{~mm}$ in length (Adhesive Dispensing, Milton Keynes, United Kingdom). A printing speed of $5 \mathrm{~mm} / \mathrm{s}$, layer thickness of $0.2 \mathrm{~mm}, 0.45 \mathrm{~mm}$ hatch spacing; providing a $10 \%$ overlap of the extruded filaments, and a constant positive displacement value of 85 pulses per microlitre, were used to print cylindrical test samples of $15 \mathrm{~mm}$ in diameter and $4 \mathrm{~mm}$ thickness. The test samples were first modelled prior to printing using CAD and G-code and Hyrel3D's s inbuilt slicing software. 
3D printed samples were left to dry at room temperature for a minimum of 24 hours. Samples were thermally debinded in a furnace (RHF 1600, Carbolite Gero Ltd, Hope, UK) in static air using a ramp rate of $1^{\circ} \mathrm{C} \cdot \mathrm{min}^{-1}$ up to $400^{\circ} \mathrm{C}$ whilst holding at $100^{\circ} \mathrm{C}, 200^{\circ} \mathrm{C}, 300^{\circ} \mathrm{C}$ and $400^{\circ} \mathrm{C}$ for 2 hours each. The debinded samples were then sintered in static air in the temperature range of $460-490{ }^{\circ} \mathrm{C}$ for 2 hours with heating and cooling rates of $3^{\circ} \mathrm{C} \cdot \mathrm{min}^{-1}$.

\subsection{Characterisation methods}

The phase assemblage and crystal structure of the as-synthesised powder and sintered AMO ceramics were investigated using X-Ray diffraction (D2 Phaser, Brucker AXS, Karlsruhe, Germany) using CuK $\alpha$ radiation at $\lambda=1.54054 \AA$, operating at $30 \mathrm{kV}$ and $10 \mathrm{~mA}$. A $1 \mathrm{~mm}$ divergence and a $3 \mathrm{~mm}$ anti-scatter slits were used. Diffraction patterns were collected in the $10-60^{\circ} 2 \vartheta$ interval, using a $0.02^{\circ}$ step size and 15/min sample rotation. Data were analysed using Brucker's proprietary software (DIFFRAC.EVA 4.2.2, Brucker AXS, Karlsruhe, Germany). To investigate further the possibility of any phase transformation taking place within the $460-490^{\circ} \mathrm{C}$, corroborative Differential Thermal Analysis (DTA) (SDT Q600) was performed on the powder in $\mathrm{N}_{2}$ using $100 \mathrm{ml} \cdot \mathrm{min}^{-1}$ purging rate at a heating rate of $10^{\circ} \mathrm{C} \cdot \mathrm{min}^{-1}$.

Rheological properties of the AMO paste were measured using a high shear rheometer (Physica MCR 101, Anton Paar) with a parallel-plate geometry of $25 \mathrm{~mm}$ in diameter and $0.5 \mathrm{~mm}$ gap. To determine the storage ( $\left(G^{\prime}\right)$ and loss modulus $(G)^{\prime \prime}$, an amplitude sweep was performed using a continuous strain ramp from 0.01 to $100 \mathrm{~s}^{-1}$.

The AMO paste was subjected to differential scanning calorimetry (DSC) (2920 Modulated DSC, TA Instruments Inc., USA), to verify the material's melting point and any thermophysical material interactions during heating. Thermogravimetric analysis (TGA) (Q5000-IR, TA Instruments Inc., USA) was used to identify the minimum temperature required for the complete burn-off of the paste's vehicle/organic matter. Both techniques were carried out under an Ar gas using a $200 \mathrm{ml} \cdot \mathrm{min}^{-1}$ purging rate at a heating rate of $10^{\circ} \mathrm{C} \cdot \mathrm{min}^{-1}$.

The density of the sintered samples was measured using the Archimedes principle. Results are reported as an average of three different 3D printed samples, together with standard error. 
The effect of sintering temperature on the ceramic microstructure was assessed using a scanning electron microscope (SEM) (TM3030, Hitachi High Energy Technologies, etc.). 3D printed test samples were embedded in epoxy resin (EpoThin2, Buehler, Illinois, USA) and prepared using a standard metallographic regime; ground using silicon carbide paper of P1200 grit size, followed by a polishing stage using a polishing cloth and a $0.05 \mu \mathrm{m}$ alumina suspension. To prevent charging during SEM, samples were sputter coated with a gold/palladium alloy in an 80:20 wt.\% ratio, for $60 \mathrm{~s}$ at $25 \mathrm{~mA}$ (Quorum Q150T, Quorum, Edwards, Hastings, UK).

Relative permittivity $\left(\varepsilon_{r}\right)$ and dielectric loss $(\tan \delta)$ of additively manufactured sintered samples were determined by placing the cylindrical 3D printed test samples of $15 \mathrm{~mm}$ diameter and $4 \mathrm{~mm}$ thickness, into a $24 \mathrm{~mm} \mathrm{TE} \mathrm{E}_{01 \delta}$ cavity resonator (QWED, Warsaw, Poland), measuring the transmission and reflection from the target sample, connected to a Vector Network Analyser (VNA) (MS465B22, Anritsu, Japan) using coaxial cables [30]. The properties were calculated using QWED's proprietary software. Results are reported as an average of 3 different printed samples, together with standard error.

A Peltier device was used to heat the cavity resonator for measuring the temperature coefficient of resonant frequency $\left(\tau_{f}\right)$ from $25{ }^{\circ} \mathrm{C}$ to $85{ }^{\circ} \mathrm{C}$. The temperature coefficient of resonant frequency was calculated with the following formula (1) where the $f_{85}$ and $f_{25}$ were the $\mathrm{TE}_{01 \delta}$ resonant frequencies at 85 ${ }^{\circ} \mathrm{C}$ and $25^{\circ} \mathrm{C}$, respectively.

$$
\tau_{f}=\frac{f_{85}-f_{25}}{f_{25}(85-25)} \times 10^{6}\left(\mathrm{ppm} /{ }^{\circ} \mathrm{C}\right)
$$




\section{Results \& Discussion}

\subsection{Raw material characterisation}

Figure 1a, shows the room-temperature diffraction patterns for the AMO powder. The diffraction peaks were indexed to the triclinic (anorthic) AMO phase (ICDD PDF 75-1505) of the P $\overline{1}$ space group, with lattice parameters of $a=6.095 \AA, b=7.501 \AA, c=7.681 \AA, \alpha=110.4^{\circ}, b=93.3^{\circ}$ and $\gamma=113.5^{\circ}$. The theoretical density using the lattice parameters was calculated at $\rho=5.8 \mathrm{~g} \cdot \mathrm{cm}^{-3}$. No traces of impurities or secondary phases were detected. Figure $\mathbf{1 b}$ depicts the complementary thermal analysis of the AMO powder via DTA, from room temperature (RT) to $600^{\circ} \mathrm{C}$. No thermophysical reactions associated with a phase transition were observed in DTA during heating, aside from an endothermic peak at $510^{\circ} \mathrm{C}$ due to melting.

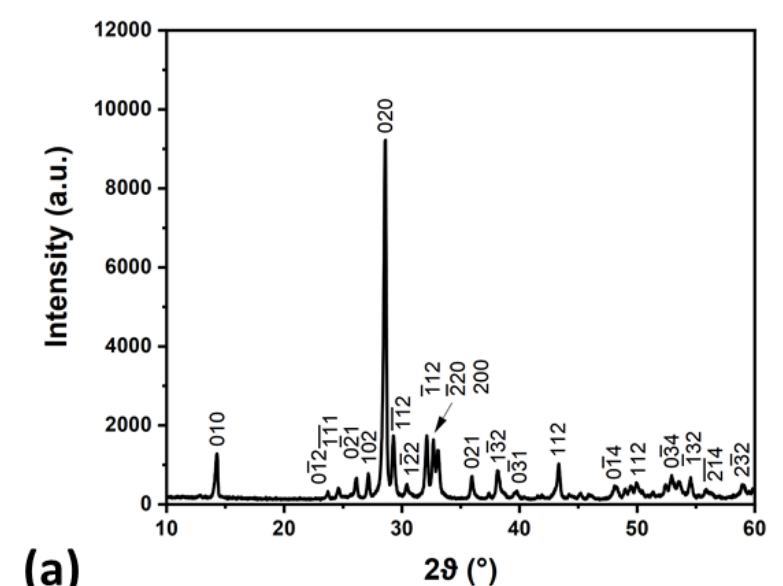

(a) $2 \vartheta\left({ }^{\circ}\right)$

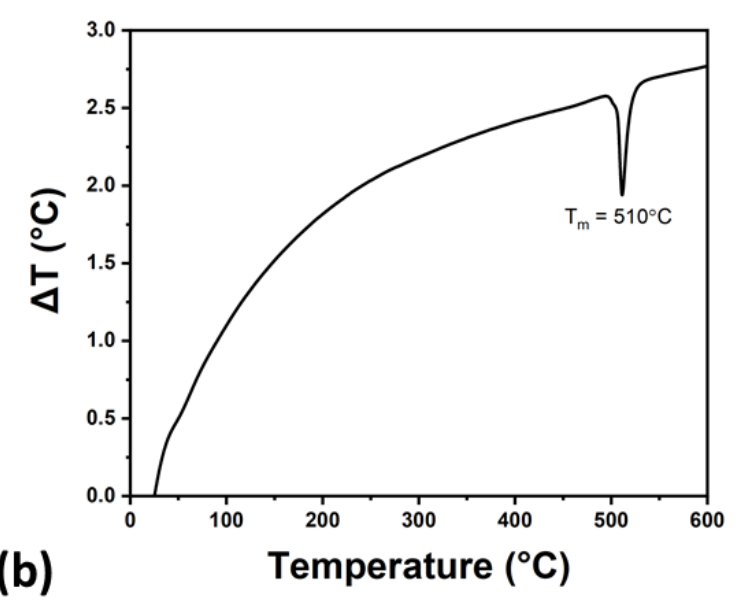

Figure 1 - (a) XRD pattern of the as-synthesised AMO powder, (b) DTA curve of the AMO powder.

\subsection{Rheological behaviour or pre-ceramic paste}

Figure $2 a$ shows the storage modulus $\left(G^{\prime}\right)$, loss modulus $\left(G^{\prime \prime}\right)$, complex viscosity $(\eta)$ of the ceramic paste used for the additive manufacturing of the cylindrical pellets that were then used for sintering and further characterisation. At low strains $(<1 \%)$, storage and loss moduli possess a linear viscoelastic (LVE) relationship with storage modulus being greater than the loss, suggesting the structural stability of the printing medium; i.e. suitable for material extrusion [31,32]. The intersection point between the moduli curves is the yield stress $\left(\mathrm{y}_{0}\right)$ required to deform the ceramic paste and facilitate flow. Practically, this also translates to the minimum amount of pressure to be applied to the syringe plunger when a pneumaticbased extrusion system is used. The yield stress point of $y_{0}=42.4 \mathrm{kPa}$ at $3.86 \%$ strain was calculated using 
an intersection script (Origin 2020, OriginLab Corporation, Northampton, MA, USA) between the storage and loss modulus curves. The effect of shear strain on viscosity is also shown where the pre-ceramic paste exhibited a characteristic reduction of its viscosity with increasing rate of deformation. The latter is commonly known as shear thinning behaviour; a fundamental requirement for printing mediums to be used with material extrusion AM processing [33].

Figure $\mathbf{2 b}$ shows the thixotropy study of the AMO ceramic paste. Thixotropy is a rheological state in which viscosity decreases with shear but some time is required for the structure to reform as shear is slowly reduced. A paste test sample was subjected to a low $\left(0.1 \mathrm{~s}^{-1}\right)-$ high $\left(4 \mathrm{~s}^{-1}\right)-\operatorname{low}\left(0.1 \mathrm{~s}^{-1}\right)$ shear deformation rate sequence where its ability to recover its initial internal structure and viscosity is assessed and the time required to do so is calculated accordingly. The AMO ceramic paste exhibited a thixotropic rebuild time (also known as hysteresis) of $30 \mathrm{~s}$ to regain its viscosity from $1.5 \mathrm{~Pa} \cdot \mathrm{s}$ to $10.0 \mathrm{kPa} \cdot \mathrm{s}$. This is another critical parameter in material extrusion, suggesting the minimum time afforded to print a monolayer. When the printing time per layer is less than the thixotropic rebuild time, the printed layer will not have regained its strength and stability to provide support for the next layers. This will also define the maximum printing speed for a stable print. Based on the above, a printing speed of $5 \mathrm{~mm} / \mathrm{s}$, taking $52 \mathrm{~s}$ printing time per layer, was chosen as optimum printing speed to additively manufacture all the AMO test samples.

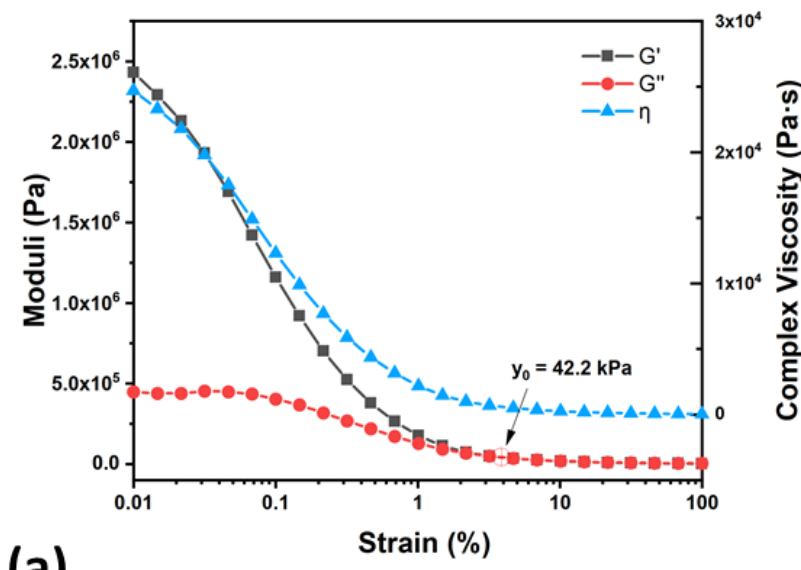

(a)

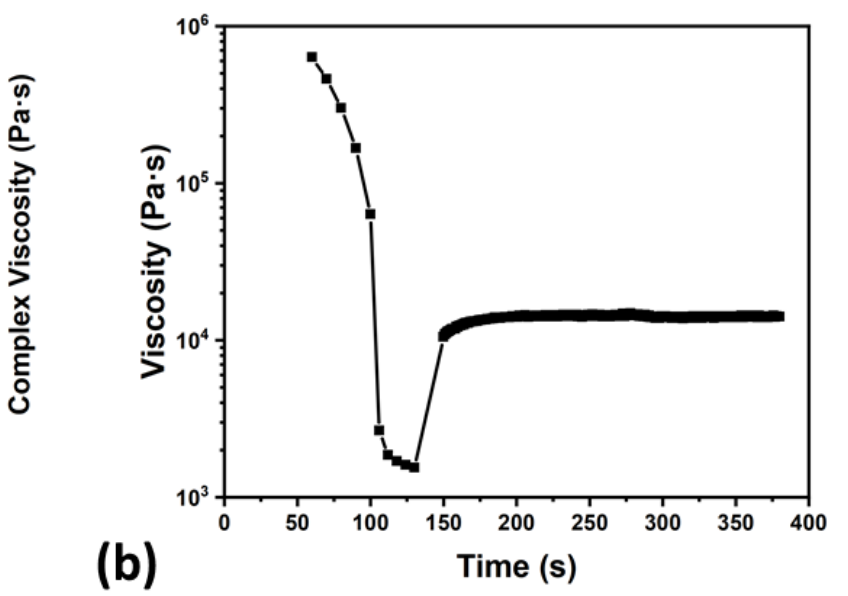

Figure 2 - Rheology data of the AMO ceramic paste formulation. 


\subsection{Thermal analysis of the AMO pre-ceramic paste}

Figure 3 shows the DSC-TGA curves of the AMO ceramic paste from RT $-600^{\circ} \mathrm{C}$. In the DSC thermogram, the range from $\mathrm{RT}$ to $400^{\circ} \mathrm{C}$ contains several endo- and exothermic peaks ascribed to the thermophysical reactions of melting, boiling and evaporation of the ceramic paste's organic components. A major endothermic peak at $T_{m}=510^{\circ} \mathrm{C}$ is associated with melting (possibly incongruent), in agreement with DTA traces, Figure 1b. This is followed by an exothermic peak at the temperature of $T_{c}=518{ }^{\circ} \mathrm{C}$, suggesting a $\mathrm{Ag}_{2} \mathrm{Mo}_{2} \mathrm{O}_{7} \rightarrow \mathrm{Ag}_{2} \mathrm{Mo}_{4} \mathrm{O}_{13}$ phase transformation as indicated by the $\mathrm{Ag}_{2} \mathrm{O}-\mathrm{MoO}_{3}$ phase diagram [34]. In the same figure, the inset TGA curve, revealed a trend of continuous weight loss of organic components from $\mathrm{RT}$ to $380^{\circ} \mathrm{C}$ above which the weight remains constant at $78.96 \%$, representatve of the wt \% of AMO ceramic powder within the paste. $400{ }^{\circ} \mathrm{C}$ was therefore, chosen for the binder-removal stage prior to sintering of the additively manufactured test samples. The presence of any residual organics within the ceramic body are expected to outgas during sintering and contribute towards increased porosity. Additionally, organic materials are known to promote reduction of oxides, giving rise to oxygen vacancies and low $Q x f($ high $\tan \delta)[6]$.

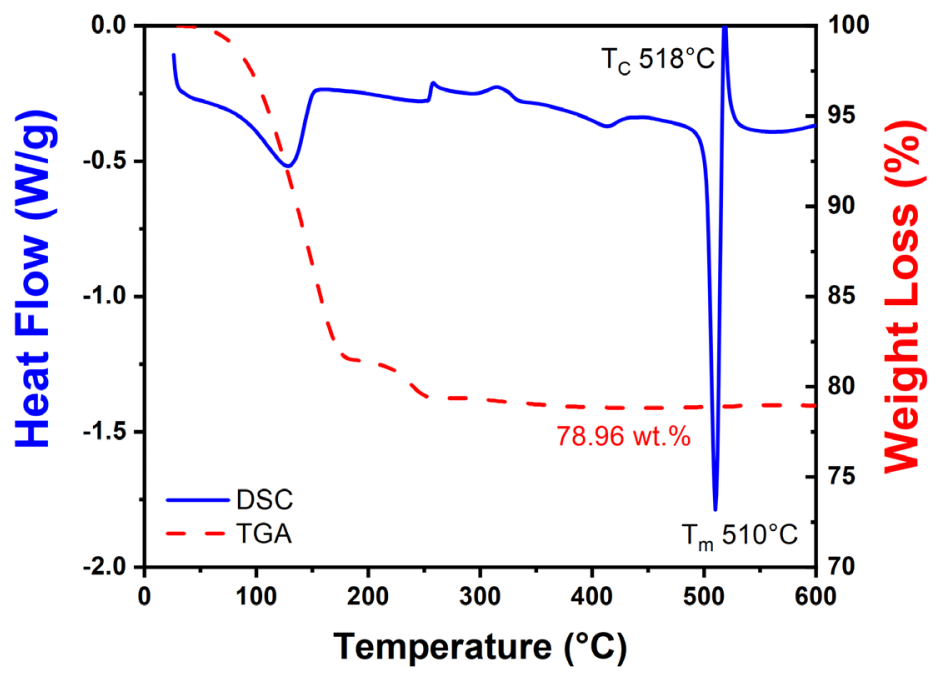

Figure 3-DSC and TGA curves overlay of AMO paste sample. 


\subsection{Physical and microwave dielectric properties of AMO ceramics.}

The RT XRD patterns of the AMO ceramic samples sintered in the $460-490^{\circ} \mathrm{C}$ temperature range are shown in Figure 4a. The XRD patterns do not reveal any new or secondary phases as a result of increasing sintering temperature. However, the intensity of the 020 diffraction peak at $28.3^{\circ}$ increases at $>470{ }^{\circ} \mathrm{C}$, indicating preferential grain growth normal to the 020 plane at the pellet's surface.
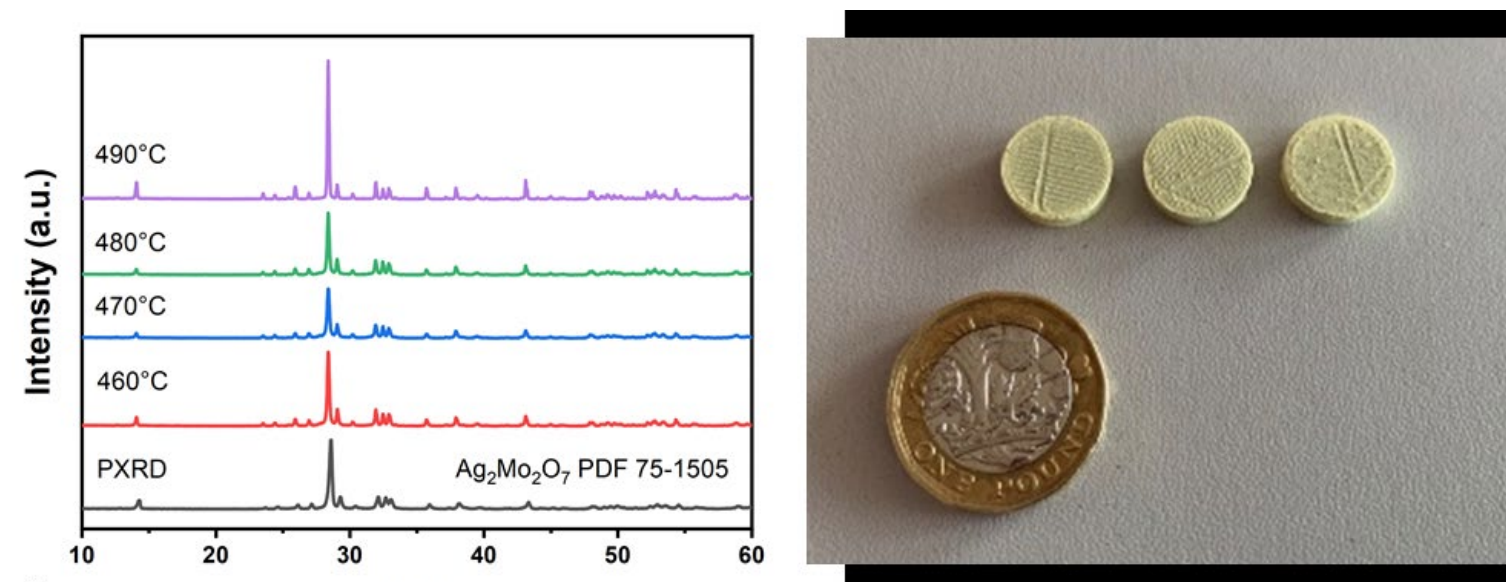

(a)

$2 \vartheta\left({ }^{\circ}\right)$

(b)

Figure 4-(a) X-Ray diffraction patterns of the AMO and (b) photo of the sintered 3D printed samples

Figure 5 shows the SEM images of the surface and cross-section microstructure of the AMO ceramic samples, sintered for 2 hours between $460-490{ }^{\circ} \mathrm{C}$ which reveal a gradual increase in grain size as a function of sintering temperature. At $460^{\circ} \mathrm{C}$, there is notable intergranular porosity as seen in the Figures (5a) and (5e). At $470{ }^{\circ} \mathrm{C}$ and $480^{\circ} \mathrm{C}$, intergranular porosity at the surface reduces as the grains enlarge but the micrographs from the cross-sectioned samples reveal that the pore size is increasing. At $490{ }^{\circ} \mathrm{C}$, larger pores are evident both at the surface and in the cross-section micrographs (Figure $5 \mathrm{~d}$ and $5 \mathrm{~h}$ ). The increase in pore size as a function of temperature is ascribed to coaleascence as the AMO grains grow which is exaggerated by their elongated morphology for which there is inefficient packing. The elongated surface grains are consistent with preferential growth normal to the 020 plane, observed by X-ray diffraction, Figure $4 a$. 

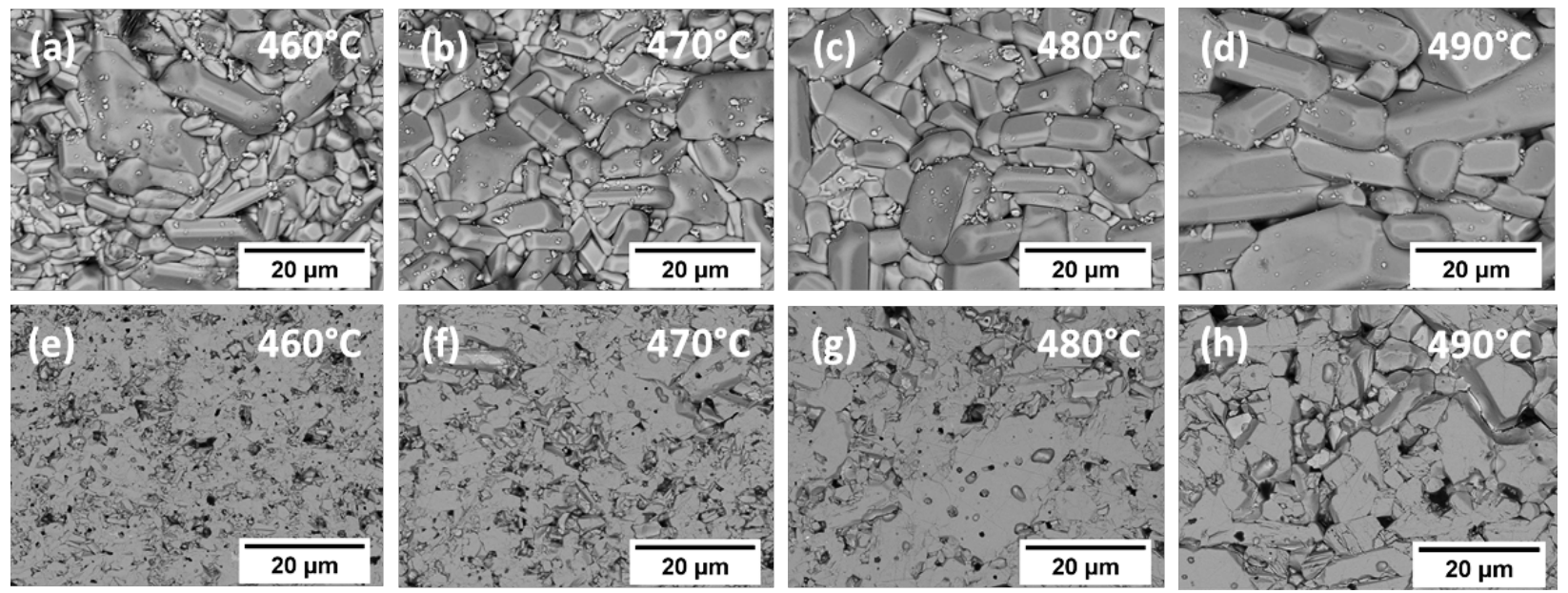

Figure 5 - SEM images of the $(a-d)$ surface and $(e-f)$ polished cross-sections of the sintered 3D printed ceramic samples.

Figure 6 shows the microwave dielectric properties and density measurements acquired from the additively manufactured sintered test samples at $460-490^{\circ} \mathrm{C} . \varepsilon_{r}$ increases as a function of sintering temperature until $470{ }^{\circ} \mathrm{C}\left(\varepsilon_{r}=13.45 \pm 0.1\right)$ but then exhibits a progressive reduction, as shown in Figure 6a. $\varepsilon_{r}$ values are in agreement with density measurements (Figure $6 \mathrm{~b}$ ) with the highest $\rho\left(5.40 \pm 0.02 \mathrm{~g}^{\circ} \mathrm{cm}^{-}\right.$ ${ }^{3}, 93 \%$ relative density) also reported at $470{ }^{\circ} \mathrm{C}$, suggesting that sintering at $>470^{\circ} \mathrm{C}$ has a negative effect on densification and permittivity. (Figure 5). Despite the low relative density (93\%), $\varepsilon_{r}=13.45 \pm 0.1$ of the additively manufactured samples of this study is similar to that previously reported in the literature [19].

Qxf values of AMO ceramic samples increase from 5,963 GHz to 22,280 GHz, with increasing sintering temperature from 460 to $490{ }^{\circ} \mathrm{C}$, as shown in Figure 6c. Of is affected by a number of factors, such as anharmonic lattice vibrations porosity, grain size and grain boundaries, defects such as microcracks and impurities phases within the ceramic body [35-39]. In this study, the primary reason for the increase in Qxf is the decrease in porosity and an increase in grain size.

Finally, $\tau_{f}$ values decrease from $-109 \mathrm{ppm} /{ }^{\circ} \mathrm{C}$ to $-133 \mathrm{ppm} /{ }^{\circ} \mathrm{C}[14,36-38]$ as sintering temperature increases. Dependence of $\tau_{f}$ on sintering temperature is well known in the processing of microwave ceramics and presents an obstacle to the control of temperature stability in commercial resonators. $\tau_{f}$ is affected by numerous factors such as grain growth, density, preferential orientation and phase assemblage. Here, the most striking difference as a function of temperature is an increase in density and exaggerated in plane grain growth at the pellet's surface. $\tau_{f}$ is an anisotropic property with different orientations of the crystal having different values. Here, we postulate that the preferred 020 orientation 
is the most likely factor influencing $\tau_{f}$ as a function of sintering temperature. We note however, that the changes in $\tau_{f}$ are comparativley modest to those of $Q x f$.

In summary, additively manufactured AMO ceramic samples sintered at $470^{\circ} \mathrm{C}$ for 2 hours exhibited optimal microwave dielectric properties of $\varepsilon_{r}=13.45, Q \times f=17,056 \mathrm{GHz}$ and $\tau_{f}=-121 \mathrm{ppm} /{ }^{\circ} \mathrm{C}$. Table 1, lists all measured properties of AMO ceramic samples.

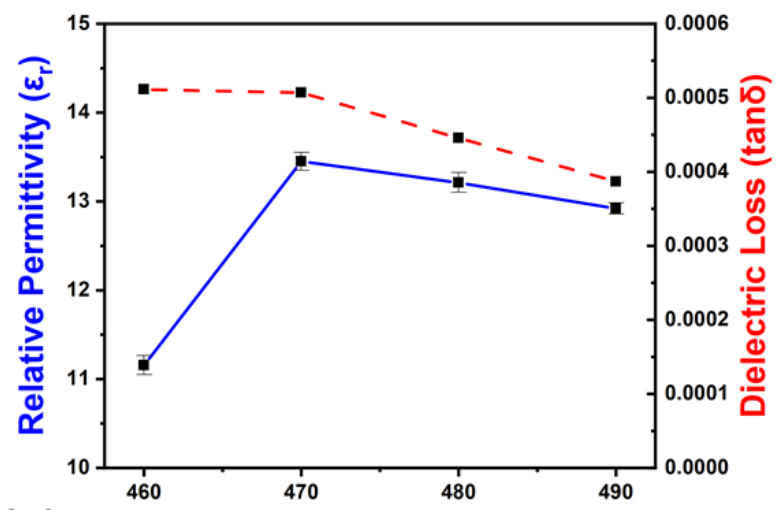

(a) Temperature $\left({ }^{\circ} \mathrm{C}\right)$

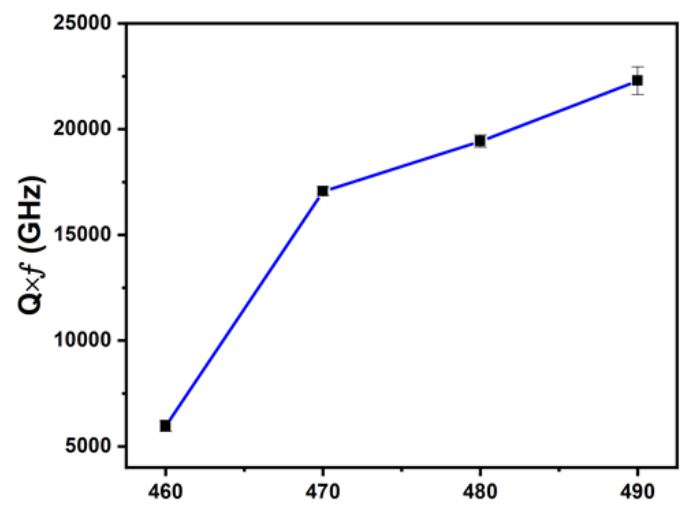

(c)

Temperature $\left({ }^{\circ} \mathrm{C}\right)$

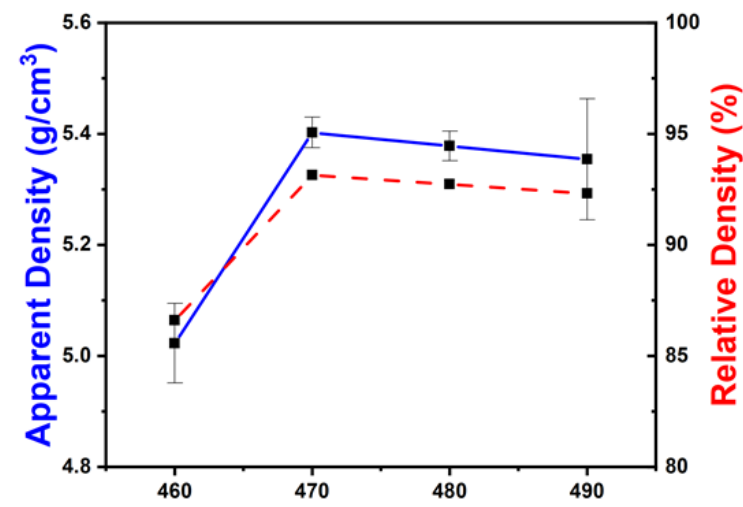

(b)

Temperature $\left({ }^{\circ} \mathrm{C}\right)$

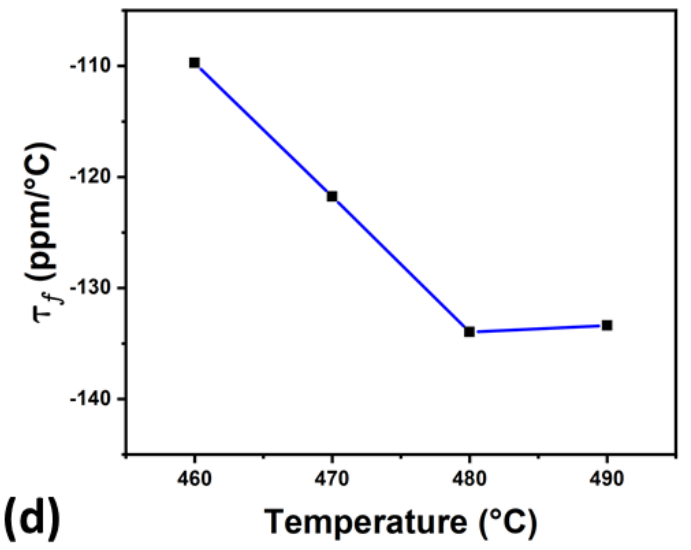

Figure 6 - The effect of sintering temperature on the microwave dielectric properties of additive manufactured AMO ceramic samples: (a) relative permittivity ( $\varepsilon_{r}$ ) and dielectric loss (tan $\delta$ ), (b) apparent and relative density, (c) quality factor $(\mathrm{Qxf})$ and $(d)$ temperature coefficient of resonant frequency $\left(\tau_{f}\right)$. 
Table 1 - The sintering temperatures, microwave dielectric properties of relative permittivity $\left(\varepsilon_{r}\right)$, dielectric loss $(\tan \delta)$, quality factor $(Q x f)$, resonance frequency coefficient $\left(\tau_{f}\right)$ and densities of the additively manufactured AMO ceramic samples.

\begin{tabular}{|c|c|c|c|c|c|c|}
\hline $\begin{array}{c}\text { Temperature } \\
\left({ }^{\circ} \mathrm{C}\right)\end{array}$ & $\varepsilon_{\mathrm{r}}$ & $\tan \delta$ & $\begin{array}{c}\text { Apparent Density } \\
\left(\mathrm{g} \cdot \mathrm{cm}^{-3}\right)\end{array}$ & $\begin{array}{c}\text { Relative } \\
\text { Density (\%) }\end{array}$ & $\mathrm{Q} \times f(\mathrm{GHz})$ & $\tau_{f}\left(\mathrm{ppm} /{ }^{\circ} \mathrm{C}\right)$ \\
\hline 460 & $11.16 \pm 0.11$ & $0.0005 \pm 0.00002$ & $5.02 \pm 0.07$ & 86.59 & $5963 \pm 265$ & -109 \\
\hline 470 & $13.45 \pm 0.10$ & $0.0005 \pm 0.000005$ & $5.40 \pm 0.03$ & 93.14 & $17057 \pm 207$ & -121 \\
\hline 480 & $13.21 \pm 0.11$ & $0.0004 \pm 0.00001$ & $5.38 \pm 0.03$ & 92.72 & $19419 \pm 289$ & -133 \\
\hline 490 & $12.92 \pm 0.06$ & $0.0004 \pm 0.00001$ & $5.35 \pm 0.11$ & 92.31 & $22280 \pm 649$ & -133 \\
\hline
\end{tabular}

\subsection{Additive manufacture of a metal/ceramic antennas}

Figure 7, depicts the first ever metal/ceramic antennas made using $\mathrm{AMO}$ and $\mathrm{Ag}$, that were designed and additively manufactured using the direct ink writing process. Given the materials' known chemical compatibility, a silver electrode paste was chosen to print the radiating element. Both an exposed (Figure $7 \mathrm{a}-\mathrm{c}$ ) and a packaged version (Figure $\mathbf{7 d - f}$ ) of microstrip antennas were manufactured using sequential printing of the conductive and dielectric materials, in a single process. Both metal/ceramic antennas were successfully co-fired at $470^{\circ} \mathrm{C}$ for 2 hours, with no macroscopic failures such as cracking after sintering.

In the first metal/ceramic antenna where the electrode patch was nested on top of the ceramic substrate, the fired structure appeared to have slightly deformed. This is ascribed to either the mismatch between the shrinkage rates and/or coefficient of thermal expansion (CTE) of the two materials. We propose that this may be addressed in future studies either by tailoring the CTE of the electrode and ceramic formulations or by controlling the heat treatment profiles of the cofired body. However, no macroscopic failures or structural deformations were evident in the case of the packaged antenna, where the electrode patch was nested inbetween the AMO substrate and superstrate. The substrate also contained a groove of $0.2 \mathrm{~mm}$ in depth, to host the metallc patch of $0.2 \mathrm{~mm}$ thickness. It is presumed that the superstrate, the additional ceramic layer above the conductive element of the antenna, helped to reduce stresses involved during the firing. No further characterisations were performed, in regards to the radiation profile and efficiency of the AMO/Ag co-fired antennas, as this was not the scope of this study. 


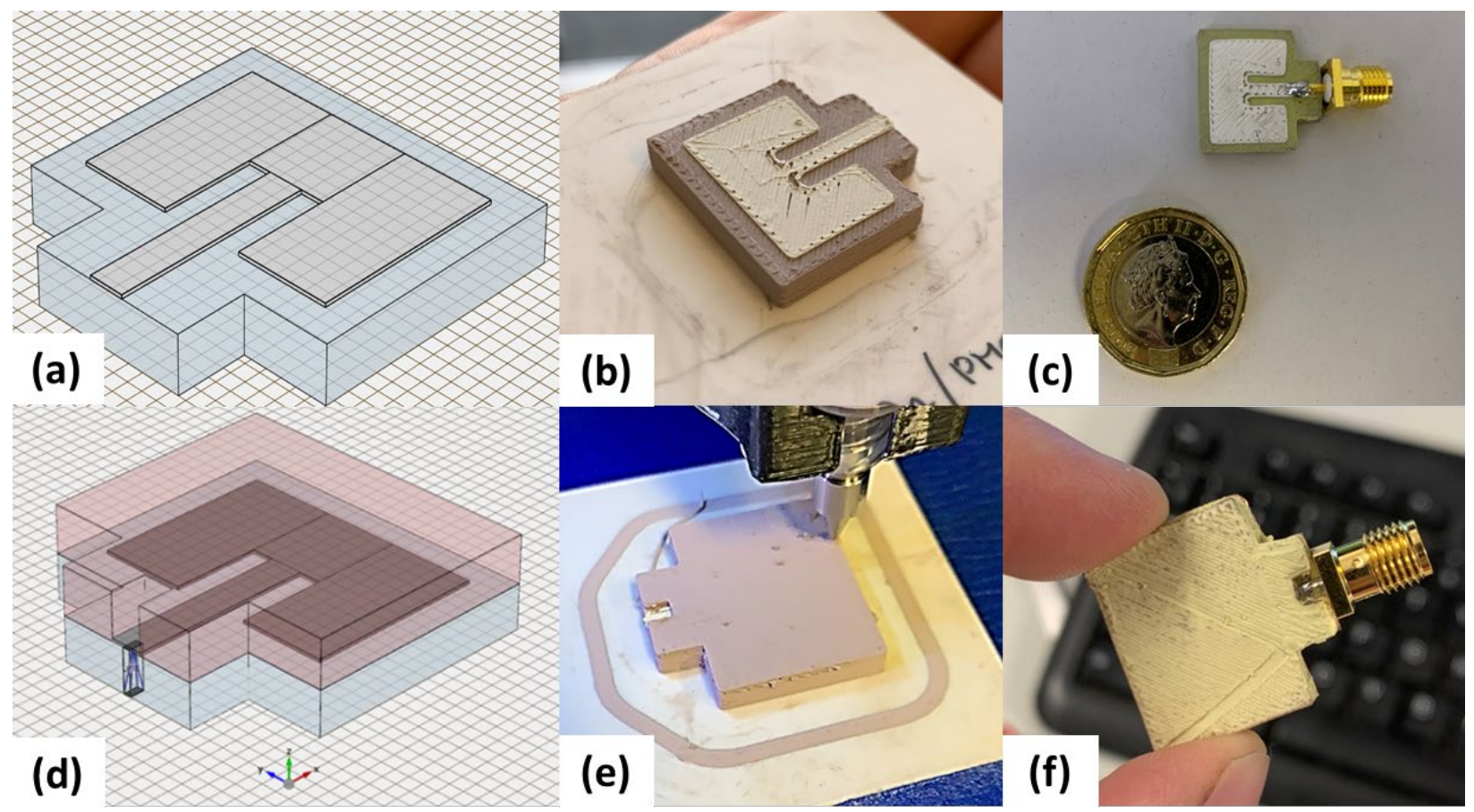

Figure 7-Additive manufactured (a-c) exposed and (d-f) packaged metal/ceramic antennas.

Figure 8, shows the SEM image of cross-section for the AMO/Ag antenna. The inset elemental maps were acquired via EDS, revealing a stable co-fired structure with no chemical reaction nor Ag diffusion between the top and bottom AMO layers. However, several micropores are evident in between the layers of the superstrate that are close to the electrode layer. Any apparent porosity is expected to hinder the resultant $\varepsilon_{\mathrm{r}}$ of the packaging constituents of the antenna assembly, thereby affecting its performance and overall efficiency which will be optimized in future work.

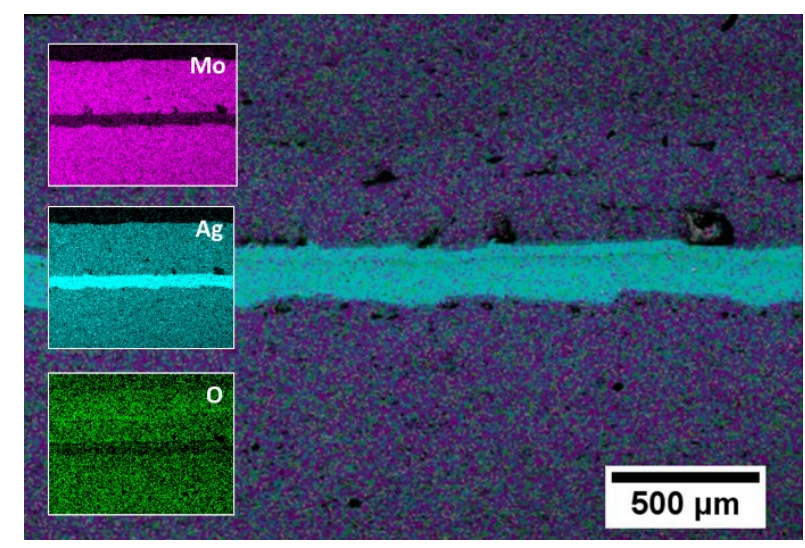

Figure 8 - Combined element EDS with inset individual element maps of the packaged metal/ceramic antenna. 


\section{Conclusions}

Material extrusion, an additive manufacturing process has been used to fabricate three-dimensional test samples, using $\mathrm{Ag}_{2} \mathrm{Mo}_{2} \mathrm{O}_{7}$, an ultra-low sintering temperature microwave ceramic. $\mathrm{Ag}_{2} \mathrm{Mo}_{2} \mathrm{O}_{7}$ ceramic green bodies were printed using a $0.2 \mathrm{~mm}$ layer thickness, $5 \mathrm{~mm} / \mathrm{s}$ printing speed, 0.45 hatch spacing, using a $0.5 \mathrm{~mm}$ nozzle. The green bodies were fired at $470{ }^{\circ} \mathrm{C}$ for 2 hours which resulted in relative density $\approx 93 \%, \varepsilon_{r}=13.45, \tan \delta=0.0005, Q \times f=17,065$ and $\tau_{f}=-121 \mathrm{ppm} /{ }^{\circ} \mathrm{C}$. A series of metal/ceramic patch antenna designs were printed and co-fired using the $\mathrm{Ag}_{2} \mathrm{Mo}_{2} \mathrm{O}_{7}$ ceramic and $\mathrm{Ag}$ electrode. No chemical incompatibility of interdiffusion was evident allowing for the first metal/ceramic antennas to be fabricated via single process multi-material extrusion.

\section{Acknowledgements}

This work was supported by EPSRC research grant SYMETA (EP/N010493/1). The authors would like to thank the experimental officers in the Loughborough Materials Characterisation Centre (LMCC) and Mrs Pauline King in the Department of Chemistry for their assistance. 


\section{References}

[1] I.M. Reaney, D. Iddles, Microwave dielectric ceramics for resonators and filters in mobile phone networks, J. Am. Ceram. Soc. 89 (2006) 2063-2072. doi:10.1111/j.1551-2916.2006.01025.X.

[2] D. Zhou, L.X. Pang, D. Wang, I.M. Reaney, BiVO4 based high: K microwave dielectric materials: A review, J. Mater. Chem. C. 6 (2018) 9290-9313. doi:10.1039/c8tc02260g.

[3] R. Muhammad, Y. Iqbal, C.R. Rambo, H. Khan, Research trends in microwave dielectrics and factors affecting their properties: A review, Int. J. Mater. Res. 105 (2014) 431-439. doi:10.3139/146.111044.

[4] D. Zhou, D. Guo, W.B. Li, L.X. Pang, X. Yao, D.W. Wang, I.M. Reaney, Novel temperature stable high$: \in \mathrm{r}$ microwave dielectrics in the Bi2O3-TiO2-V2O5 system, J. Mater. Chem. C. 4 (2016) 5357-5362. doi:10.1039/c6tc01431c.

[5] D. Zhou, J. Li, L.X. Pang, G.H. Chen, Z.M. Qi, D.W. Wang, I.M. Reaney, Crystal Structure, Infrared Spectra, and Microwave Dielectric Properties of Temperature-Stable Zircon-Type (Y,Bi)VO4 SolidSolution Ceramics, ACS Omega. 1 (2016) 963-970. doi:10.1021/acsomega.6b00274.

[6] M.T. Sebastian, R. Ubic, H. Jantunen, Low-loss dielectric ceramic materials and their properties, Int. Mater. Rev. 60 (2015) 392-412. doi:10.1179/1743280415Y.0000000007.

[7] Q. Lin, K. Song, B. Liu, H.B. Bafrooei, D. Zhou, W. Su, F. Shi, D. Wang, H. Lin, I. M.Reaney, Vibrational spectroscopy and microwave dielectric properties of $\mathrm{AY} 2 \mathrm{Si} 3010(\mathrm{~A}=\mathrm{Sr}, \mathrm{Ba})$ ceramics for $5 \mathrm{G}$ applications, Ceram. Int. 46 (2020) 1171-1177. doi:10.1016/j.ceramint.2019.09.086.

[8] Z. Tan, K. Song, H.B. Bafrooei, B. Liu, J. Wu, J. Xu, H. Lin, D. Wang, The effects of TiO2 addition on microwave dielectric properties of Y3MgAl3SiO12 ceramic for 5G application, Ceram. Int. 46 (2020) 15665-15669. doi:10.1016/j.ceramint.2020.03.116.

[9] Z. Song, K. Song, B. Liu, P. Zheng, H. Barzegar Bafrooei, W. Su, H. Lin, F. Shi, D. Wang, I.M. Reaney, Temperature-dependent dielectric and Raman spectra and microwave dielectric properties of gehlenite-type Ca2Al2SiO7 ceramics, Int. J. Appl. Ceram. Technol. 17 (2020) 771-777. doi:10.1111/ijac.13414.

[10] D. Zhou, L.X. Pang, D.W. Wang, Z.M. Qi, I.M. Reaney, High Quality Factor, Ultralow Sintering Temperature Li6B4O9 Microwave Dielectric Ceramics with Ultralow Density for Antenna Substrates, ACS Sustain. Chem. Eng. 6 (2018) 11138-11143. doi:10.1021/acssuschemeng.8b02755.

[11] L.X. Pang, D. Zhou, D.W. Wang, J.X. Zhao, W.G. Liu, Z.X. Yue, I.M. Reaney, Temperature stable K0.5(Nd1-xBix)0.5MoO4 microwave dielectrics ceramics with ultra-low sintering temperature, J. 
Am. Ceram. Soc. 101 (2018) 1806-1810. doi:10.1111/jace.15388.

[12] D. Zhou, L.X. Pang, D.W. Wang, H.H. Guo, F. Yang, Z.M. Qi, C. Li, B.B. Jin, I.M. Reaney, Crystal structure, impedance and broadband dielectric spectra of ordered scheelite-structured $\mathrm{Bi}(\mathrm{Sc} 1 / 3 \mathrm{Mo2} / 3) \mathrm{O} 4$ ceramic, J. Eur. Ceram. Soc. 38 (2018) 1556-1561. doi:10.1016/j.jeurceramsoc.2017.12.044.

[13] S.Z. Hao, D. Zhou, F. Hussain, W.F. Liu, J.Z. Su, D.W. Wang, Q.P. Wang, Z.M. Qi, C. Singh, S. Trukhanov, Structure, spectral analysis and microwave dielectric properties of novel $\mathrm{x}(\mathrm{NaBi}) 0.5 \mathrm{MoO} 4-(1-\mathrm{x}) \mathrm{Bi} 2 / 3 \mathrm{MoO} 4(\mathrm{x}=0.2 \sim 0.8)$ ceramics with low sintering temperatures, J. Eur. Ceram. Soc. 40 (2020) 3569-3576. doi:10.1016/j.jeurceramsoc.2020.03.074.

[14] D. Wang, S. Zhang, D. Zhou, K. Song, A. Feteira, J.C. Vardaxoglou, W. Whittow, D. Cadman, I.M. Reaney, Temperature Stable Cold Sintered (Bi0.95Li0.05)(V0.9Mo0.1)O4-Na2Mo2O7 Microwave Dielectric Composites, Materials (Basel). 12 (2019). doi:doi:10.3390/ma12091370.

[15] D. Zhou, H. Wang, X. Yao, L.-X. Pang, Microwave Dielectric Properties of Low Temperature Firing Bi 2 Mo 2 O g Ceramic, J. Am. Ceram. Soc. 91 (2008) 3419-3422. doi:10.1111/j.15512916.2008.02596.x.

[16] L.X. Pang, G. Bin Sun, D. Zhou, Ln2Mo3012 ( $\mathrm{Ln}=\mathrm{La}, \mathrm{Nd}$ ): A novel group of low loss microwave dielectric ceramics with low sintering temperature, Mater. Lett. 65 (2011) 164-166. doi:10.1016/j.matlet.2010.09.064.

[17] D. Zhou, L.X. Pang, D.W. Wang, I.M. Reaney, Novel water-assisting low firing MoO3 microwave dielectric ceramics, J. Eur. Ceram. Soc. 39 (2019) 2374-2378. doi:10.1016/j.jeurceramsoc.2019.01.052.

[18] D. Zhou, W.-B. Li, L.-X. Pang, J. Guo, Z.-M. Qi, T. Shao, Z.-X. Yue, X. Yao, Sintering Behavior and Dielectric Properties of Ultra-Low Temperature Fired Silver Molybdate Ceramics, J. Am. Ceram. Soc. 97 (2014) 3597-3601. doi:10.1111/jace.13159.

[19] G.Q. Zhang, J. Guo, H. Wang, Ultra-low temperature sintering microwave dielectric ceramics based on Ag2O-MoO3binary system, J. Am. Ceram. Soc. 100 (2017) 2604-2611. doi:10.1111/jace.14760.

[20] D.W. Kim, I.S. Cho, S. Lee, S.T. Bae, S.S. Shin, G.S. Han, H.S. Jung, K.S. Hong, Photophysical and photocatalytic properties of Ag2M 207 (M=Mo, W), J. Am. Ceram. Soc. 93 (2010) 3867-3872. doi:10.1111/j.1551-2916.2010.03972.x.

[21] Z. Jiao, Z. Liu, Z. Ma, Rodlike Agl/Ag 2 Mo 207 Heterojunctions with Enhanced Visible-Light-Driven Photocatalytic Activity, ACS Omega. 4 (2019) 7919-7930. doi:10.1021/acsomega.9b00806.

[22] K. Saito, S. Kazama, K. Matsubara, T. Yui, M. Yagi, Monoclinic Ag2Mo2O7 nanowire: A new Ag-Mo- 
O nanophotocatalyst material, Inorg. Chem. 52 (2013) 8297-8299. doi:10.1021/ic401236b.

[23] N. Chen, Y. Gao, M. Zhang, X. Meng, C. Wang, Y. Wei, F. Du, G. Chen, Electrochemical Properties and Sodium-Storage Mechanism of Ag2Mo2O7 as the Anode Material for Sodium-lon Batteries, Chem. - A Eur. J. 22 (2016) 7248-7254. doi:10.1002/chem.201600224.

[24] E.Y. Liu, Y.M. Gao, W.Z. Wang, X.L. Zhang, X. Wang, G.W. Yi, J.H. Jia, Effect of Ag2Mo2O7 incorporation on the tribological characteristics of adaptive $\mathrm{Ni}$-based composite at elevated temperatures, Tribol. Trans. 56 (2013) 469-479. doi:10.1080/10402004.2012.763004.

[25] D. Stone, J. Liu, D.P. Singh, C. Muratore, A.A. Voevodin, S. Mishra, C. Rebholz, Q. Ge, S.M. Aouadi, Layered atomic structures of double oxides for low shear strength at high temperatures, Scr. Mater. 62 (2010) 735-738. doi:10.1016/j.scriptamat.2010.02.004.

[26] R. Gheisari, H. Chamberlain, G. Chi-Tangyie, S. Zhang, A. Goulas, C.K. Lee, T. Whittaker, D. Wang, A. Ketharam, A. Ghosh, B. Vaidhyanathan, W. Whittow, D. Cadman, Y.C. Vardaxoglou, I.M. Reaney, D.S. Engstrøm, Multi-material additive manufacturing of low sintering temperature Bi2Mo209 ceramics with Ag floating electrodes by selective laser burnout, Virtual Phys. Prototyp. 15 (2020) 133-147. doi:10.1080/17452759.2019.1708026.

[27] J.E. Smay, S.S. Nadkarni, J. Xu, Direct writing of dielectric ceramics and base metal electrodes, Int. J. Appl. Ceram. Technol. 4 (2007) 47-52. doi:10.1111/j.1744-7402.2007.02118.x.

[28] U. Robles, J. Kasemodel, J. Avila, T. Benitez, R.C. Rumpf, 3-D Printed Structures by Microdispensing Materials Loaded with Dielectric and Magnetic Powders, IEEE Trans. Components, Packag. Manuf. Technol. 8 (2018) 492-498. doi:10.1109/TCPMT.2017.2781723.

[29] J. Perelaer, P.J. Smith, D. Mager, D. Soltman, S.K. Volkman, V. Subramanian, J.G. Korvink, U.S. Schubert, Printed electronics: the challenges involved in printing devices, interconnects, and contacts based on inorganic materials, J. Mater. Chem. 20 (2010) 8446. doi:10.1039/c0jm00264j.

[30] C. Lee, J. McGhee, C. Tsipogiannis, S. Zhang, D. Cadman, A. Goulas, T. Whittaker, R. Gheisari, D. Engstrom, J. (Yiannis) Vardaxoglou, W. Whittow, Evaluation of Microwave Characterization Methods for Additively Manufactured Materials, Designs. 3 (2019). doi:10.3390/designs3040047.

[31] J. Bourret, I. El Younsi, M. Bienia, A. Smith, P.M. Geffroy, J. Marie, Y. Ono, T. Chartier, V. Pateloup, Micro extrusion of innovative alumina pastes based on aqueous solvent and eco-friendly binder, J. Eur. Ceram. Soc. 38 (2018) 2802-2807. doi:10.1016/j.jeurceramsoc.2018.02.018.

[32] A. M'Barki, L. Bocquet, A. Stevenson, Linking Rheology and Printability for Dense and Strong Ceramics by Direct Ink Writing, Sci. Rep. 7 (2017). doi:10.1038/s41598-017-06115-0.

[33] S. Mueller, L. E.W., H.M. Mader, The rheology of suspentions of solid particles, Proc. R. Soc. A. 
(2009) 291-300. doi:10.1007/BF01432034.

[34] E. Wenda, Phase diagram of the V2O5-MoO3-Ag2O system II. Phase diagram of MoO3-Ag2O system, J. Therm. Anal. 36 (1990) 1417-1427.

[35] S.J. Penn, N.M. Alford, A. Templeton, X. Wang, M. Xu, M. Reece, K. Schrapel, Effect of Porosity and Grain Size on the Microwave Dielectric Properties of Sintered Alumina, J. Am. Ceram. Soc. 80 (2005) 1885-1888. doi:10.1111/j.1151-2916.1997.tb03066.x.

[36] D. Wang, B. Siame, S. Zhang, G. Wang, X. Ju, J. Li, Z. Lu, Y. Vardaxoglou, W. Whittow, D. Cadman, S. Sun, D. Zhou, K. Song, I.M. Reaney, Direct Integration of Cold Sintered, Temperature-Stable Bi2Mo2O9-K2MoO4 Ceramics on Printed Circuit Boards for Satellite Navigation Antennas, J. Eur. Ceram. Soc. (2020) 0-1. doi:10.1016/j.jeurceramsoc.2020.04.025.

[37] D. Wang, S. Zhang, G. Wang, Y. Vardaxoglou, W. Whittow, D. Cadman, D. Zhou, K. Song, I.M. Reaney, Cold sintered CaTiO3-K2MoO4 microwave dielectric ceramics for integrated microstrip patch antennas, Appl. Mater. Today. 18 (2020) 100519. doi:10.1016/j.apmt.2019.100519.

[38] D. Wang, D. Zhou, K. Song, A. Feteira, C.A. Randall, I.M. Reaney, Cold-Sintered COG Multilayer Ceramic Capacitors, Adv. Electron. Mater. 5 (2019) 1-5. doi:10.1002/aelm.201900025. 